Check for updates

Cite this: RSC Adv., 2020, 10, 26414

Received 16th May 2020

Accepted 30th June 2020

DOI: $10.1039 / \mathrm{dOra04367b}$

rsc.li/rsc-advances

\section{A nickel-catalyzed tandem reaction involving cyclic esterification/C-S bond formation for synthesizing 5-oxa-11-thia-benzofluoren-6-ones $\dagger$}

\author{
Rongrong Cai, Qicai Wei and Runsheng Xu (DD *
}

\begin{abstract}
A nickel-catalyzed tandem reaction involving cyclic esterification/C-S bond formation has been developed. Starting from samples containing 3-(2-hydroxy-phenyl)-acrylic acids with 2-halide-benzenethiols, versatile biologically active 5-oxa-11-thia-benzofluoren-6-one compounds were efficiently synthesized in good to high yields. This new methodology provides an economical approach toward $\mathrm{C}-\mathrm{S}$ bond formation.
\end{abstract}

Sulfur-containing organic compounds have been widely applied in syntheses of pharmaceutical and functional materials. ${ }^{1}$ Due to its relatively large atomic radius and high electron density, sulfur displays relatively high reactivity and is easy to modify, at least in theory. ${ }^{2}$ In recent decades, the activation of the $\mathrm{C}-\mathrm{H}$ bond is considered as one of the most useful C-S bond formation strategies (Scheme 1a). However, compared to C-X (X $=\mathrm{I}, \mathrm{Br}, \mathrm{Cl})$ cross-coupling, direct $\mathrm{C}-\mathrm{S}$ bond cross-coupling reactions require harsher conditions and more activated reaction systems (Scheme 1b). ${ }^{3}$ Given the present challenges, the development of more efficient and environmentally friendly chemical processes for drug discovery is required. ${ }^{4}$

5-Oxa-11-thia-benzofluoren-6-one constitutes the central core unit of a variety of natural polycyclic lactones with important biological activities, including anticancer, antibacterial, antimyotoxic, and phytoalexin effects. ${ }^{5} \mathrm{~A}$ wide range of biological properties make 5-oxa-11-thia-benzofluoren-6-ones interesting synthetic targets for chemists. Several synthetic

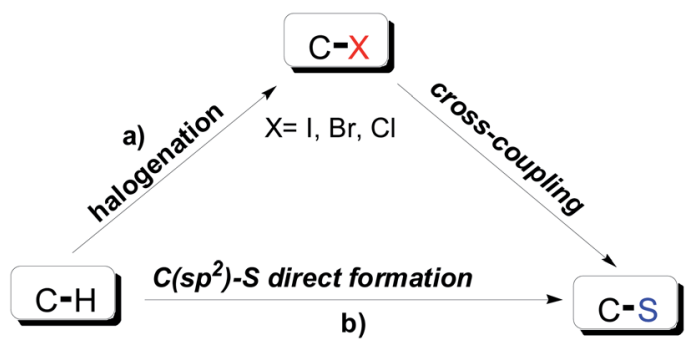

Scheme 1 C-S bond formation synthesis approaches.

Department of Biology and Environment, Jiyang College of Zhejiang A\&F University, Shaoxing 311800, Zhejiang, China. E-mail: 20140041@zafu.edu.cn

$\dagger$ Electronic supplementary information (ESI) available. See DOI: $10.1039 /$ dora04367b

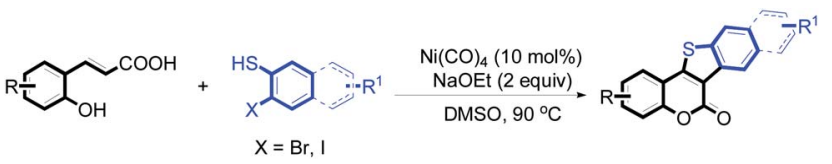

Scheme 2 The nickel-catalyzed tandem reaction for cyclic esterification/C-S bond formation.

Table 1 Optimization of the reaction conditions ${ }^{a}$

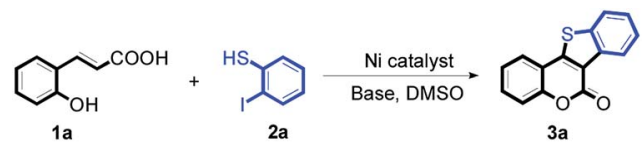

\begin{tabular}{|c|c|c|c|c|}
\hline Entry & Ni catalyst & Base & $1 a: 2 a$ & $3 a^{b}(\%)$ \\
\hline 1 & $\mathrm{NiCl}_{2}$ & $\mathrm{Na}_{2} \mathrm{CO}_{3}$ & $1: 1$ & $\mathrm{nr}$ \\
\hline 2 & $\mathrm{NiBr}_{2}$ & $\mathrm{Na}_{2} \mathrm{CO}_{3}$ & $1: 1$ & 36 \\
\hline 3 & $\mathrm{NiSO}_{4}$ & $\mathrm{Na}_{2} \mathrm{CO}_{3}$ & $1: 1$ & 44 \\
\hline 4 & $\left(\mathrm{PCy}_{3}\right)_{2} \mathrm{NiCl}_{2}$ & $\mathrm{Na}_{2} \mathrm{CO}_{3}$ & $1: 1$ & 39 \\
\hline 5 & $(\mathrm{DPPE}) \mathrm{NiCl}_{2}$ & $\mathrm{Na}_{2} \mathrm{CO}_{3}$ & $1: 1$ & 55 \\
\hline 6 & $\left(\mathrm{PPh}_{3}\right)_{2} \mathrm{NiCl}_{2}$ & $\mathrm{Na}_{2} \mathrm{CO}_{3}$ & $1: 1$ & 30 \\
\hline 7 & $\mathrm{Ni}(\mathrm{CO})_{4}$ & $\mathrm{Cs}_{2} \mathrm{CO}_{3}$ & $1: 1$ & 77 \\
\hline 8 & $\mathrm{Ni}(\mathrm{CO})_{4}$ & $\mathrm{NaOH}$ & $1: 1$ & 65 \\
\hline 9 & $\mathrm{Ni}(\mathrm{CO})_{4}$ & $\mathrm{Na}_{2} \mathrm{SO}_{4}$ & $1: 1$ & 50 \\
\hline 10 & $\mathrm{Ni}(\mathrm{CO})_{4}$ & NaOEt & $1: 1$ & 54 \\
\hline 11 & $\mathrm{Ni}(\mathrm{CO})_{4}$ & $\mathrm{NEt}_{3}$ & $1: 1$ & 46 \\
\hline 12 & $\mathrm{Ni}(\mathrm{CO})_{4}$ & NaOEt & $1: 1.2$ & 83 \\
\hline 13 & $\mathrm{Ni}(\mathrm{CO})_{4}$ & NaOEt & $1: 1.2$ & $68^{c}$ \\
\hline 14 & $\mathrm{Ni}(\mathrm{CO})_{4}$ & NaOEt & $1: 1.2$ & $75^{d}$ \\
\hline 15 & $\mathrm{Ni}(\mathrm{CO})_{4}$ & NaOEt & $1: 1.2$ & $73^{e}$ \\
\hline 16 & $\mathrm{Ni}(\mathrm{CO})_{4}$ & NaOEt & $1: 1.2$ & $54^{f}$ \\
\hline
\end{tabular}

${ }^{a}$ Unless otherwise noted, reaction conditions were $1 \mathrm{a}(0.5 \mathrm{mmol}), 2 \mathrm{a}$ ( $0.5 \mathrm{mmol})$, nickel catalyst (10 mol\%), base (2 equiv.), DMSO $(5 \mathrm{~mL})$, $90{ }^{\circ} \mathrm{C}$, and a reaction time of $10 \mathrm{~h}$. ${ }^{b}$ Isolated yield. ${ }^{c}$ At $80^{\circ} \mathrm{C} .{ }^{d} \mathrm{At}$ $100{ }^{\circ} \mathrm{C} .{ }^{e}$ In $\mathrm{CHCl}_{3} .{ }^{f}$ In DMF. 
Table 2 Nickel-catalyzed tandem reactions of 3-(2-hydroxy-phenyl)acrylic acids 1 and 2-iodo-benzenethiols 2, each involving cyclic esterification/C-S bond formation ${ }^{a}$

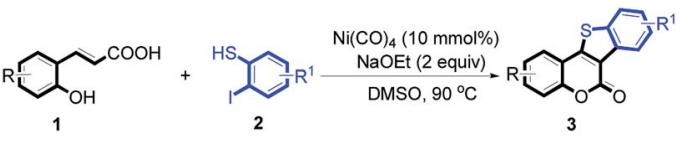

\begin{tabular}{lllll}
\hline Entry & $\mathrm{R}$ & $\mathrm{R}^{1}$ & 3 & Yield $^{b}$ \\
\hline
\end{tabular}

1

$\mathrm{H}$

$\mathrm{H}$

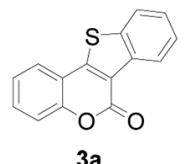

$\mathrm{H}$

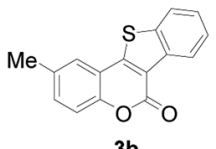

3b

3

$5-\mathrm{CH}_{3}$

Naphthyl

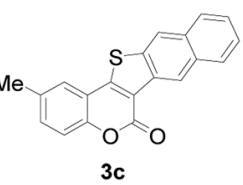

86

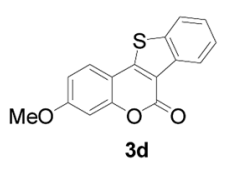

$4,5-\mathrm{diCH}_{3} \mathrm{O}$

5

4- $\mathrm{CH}_{3} \mathrm{O}$

$4-\mathrm{CH}_{3} \mathrm{O}$

Naphthyl

6 (

$5-\mathrm{F}$

$\mathrm{H}$
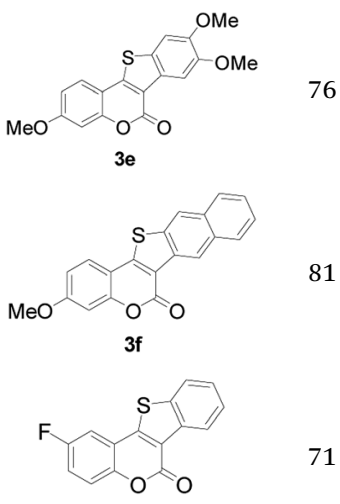

$3 \mathrm{~g}$

8

5-Cl

H

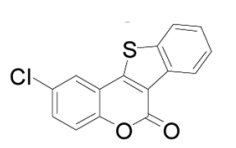

3h

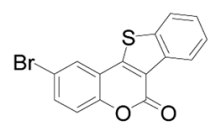

$3 \mathbf{i}$

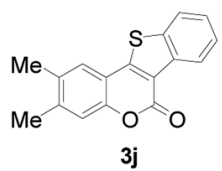

83

84
Table 2 (Contd.)

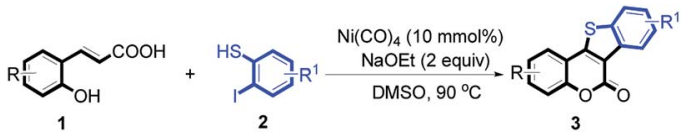

\begin{tabular}{lllll}
\hline Entry & $\mathrm{R}$ & $\mathrm{R}^{1}$ & 3 & Yield $^{b}$ \\
\hline
\end{tabular}

11

4,5- $-\mathrm{diCH}_{3} \mathrm{O}$

Naphthyl

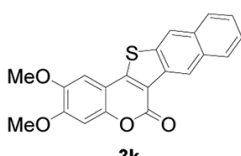

72

${ }^{a}$ Unless otherwise noted, reaction conditions were 1 (0.5 mmol), 2 (0.6 $\mathrm{mmol}), \mathrm{Ni}(\mathrm{CO})_{4}(10 \mathrm{~mol} \%)$, NaOEt (2 equiv.), DMSO $(5 \mathrm{~mL}), 90{ }^{\circ} \mathrm{C}$ and a reaction time of $10 \mathrm{~h} .{ }^{b}$ Isolated yield.

methods have been developed for the construction of this privileged structural unit. ${ }^{6}$ Most of the reported procedures involve multiple steps with moderate overall yields. The starting materials are often not very readily available. And harsh reaction conditions are usually required. In view of these limitations, the development of an efficient strategy for synthesizing 5-oxa-11-thia-benzofluoren-6-ones is highly desirable. Herein, we report a novel nickel-catalyzed tandem reaction involving cyclic esterification/C-S bond formation (Scheme 2). Versatile biologically active 5-oxa-11-thia-benzofluoren-6-one compounds were efficiently synthesized in good to high yields under mild conditions. This new methodology was concluded to provide an economical approach toward $\mathrm{C}-\mathrm{S}$ bond formation.

At first, the reaction conditions were screened based on the model reaction of 3-(2-hydroxy-phenyl)-acrylic acid 1a with 2iodo-benzenethiol 2a (Table 1). The structure of 3a was confirmed from ${ }^{1} \mathrm{H}$ NMR, ${ }^{13} \mathrm{C}$ NMR, and HRMS analyses. Various nickel-containing catalysts were tested, and displayed good catalytic activities in the presence of $\mathrm{Na}_{2} \mathrm{CO}_{3}$ (entries 1-7), with the $\mathrm{Ni}(\mathrm{CO})_{4}$ catalyst exhibiting the best catalytic efficiency (entry 7). Various bases were also tested, and NaOEt was found to be the optimal base (entry 12), having produced the product 3a with an $83 \%$ yield. Better results were also obtained when using a $1: 1.2$ ratio of 1 a to 2 a than when using a $1: 1$ ratio (entries 10 and 12). Also, under these optimized conditions, the product yield was better when the reaction temperature was $90{ }^{\circ} \mathrm{C}$ than when it was $80{ }^{\circ} \mathrm{C}$ or $100{ }^{\circ} \mathrm{C}$ (entries 12,13 and 14 ). Furthermore, the results also showed that the reaction yield was higher when using DMSO as the solvent than when using $\mathrm{CHCl}_{3}$ or DMF as the solvent (entries 12, 15 and 16). Thus, the optimum reaction condition was determined to be that involving reacting $1 \mathrm{a}$ and $\mathbf{2 a}$ in a $1: 1.2$ ratio in the presence of $\mathrm{Ni}(\mathrm{CO})_{4}(10 \mathrm{~mol} \%)$ and NaOEt (2 equiv.) in DMSO $(5 \mathrm{~mL})$ at $90{ }^{\circ} \mathrm{C}$ for 10 hours (Table 1 , entry 12 ).

Next, a wide array of 3-(2-hydroxy-phenyl)-acrylic acids $\mathbf{1}$ and 2-iodo-benzenethiols 2 were subjected to this reaction, and provided the products 3 with good to excellent yields (69-89\%, 
Table 2). 3-(2-Hydroxy-phenyl)-acrylic acids $\mathbf{1}$ bearing each an electron-donating group ( $\mathrm{Me}$ and $\mathrm{MeO}$ ) demonstrated better activity levels than did those bearing each an electronwithdrawing group (F, Cl, and $\mathrm{Br}$ ). 2-Iodo-benzenethiols 2 bearing each an electron-withdrawing group also demonstrated better activity than did those bearing each an electron-donating group. Notably, use of very strong electron-withdrawing groups, such as trifluoromethyl and nitro groups, failed to lead to the corresponding products.

Furthermore, other 3-(2-hydroxy-phenyl)-acrylic acids 1 with 2-bromo-benzenethiols $\mathbf{4}$ also successfully provided the corresponding products (Table 3). 3-(2-Hydroxy-4,5dimethoxy-phenyl)-acrylic acid displayed a moderate reactivity with chlorobenzene, and the corresponding yield was

Table 3 Nickel-catalyzed tandem reactions of 3-(2-hydroxy-phenyl)acrylic acids 1 with 2-bromo-benzenethiols 4, each involving cyclic esterification/C $-\mathrm{S}$ bond formation ${ }^{a}$

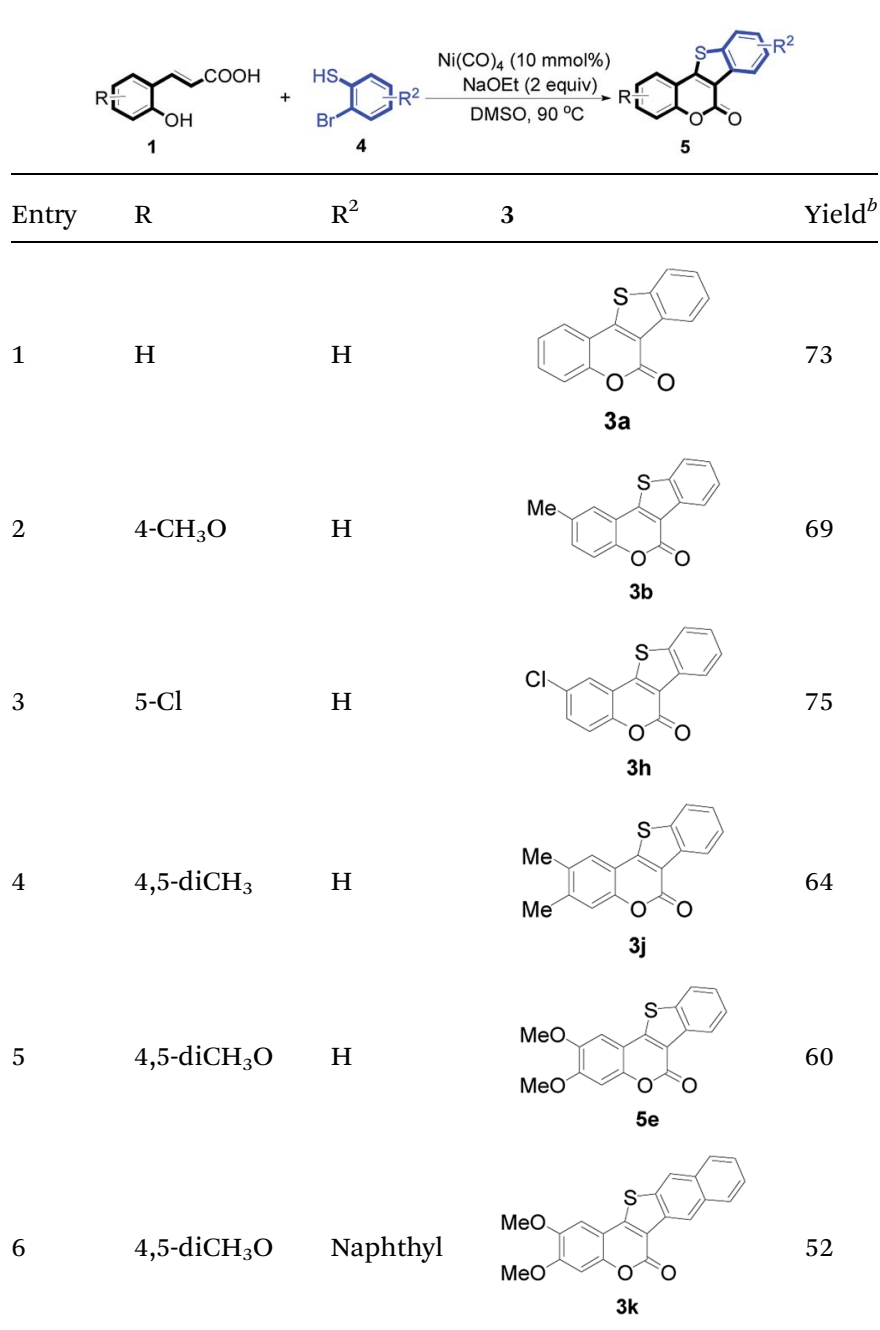

${ }^{a}$ Unless otherwise noted, reaction conditions were 1 (0.5 mmol), 3 (0.6 $\mathrm{mmol}), \mathrm{Ni}(\mathrm{CO})_{4}(10 \mathrm{~mol} \%)$, NaOEt (2 equiv.), DMSO $(5 \mathrm{~mL}), 90{ }^{\circ} \mathrm{C}$, and a reaction time of $10 \mathrm{~h} .{ }^{b}$ Isolated yield.
$64 \%$ (entry 4). Furthermore, to our delight, reactants with more substituents also proceeded smoothly (entry 6).

\section{Conclusions}

In summary, we have reported a nickel-catalyzed tandem reaction involving cyclic esterification/C-S bond formation. Starting from samples of 3-(2-hydroxy-phenyl)-acrylic acids with 2-halide-benzenethiols, versatile biologically active 5-oxa-11thia-benzofluoren-6-one compounds were efficiently synthesized in good to high yields. This new methodology provides an economical approach toward $\mathrm{C}-\mathrm{S}$ bond formation.

\section{Conflicts of interest}

There are no conflicts to declare.

\section{Acknowledgements}

Financial support was provided by the Natural Science Foundation of China (No. 21702186).

\section{Notes and references}

1 (a) S. V. Ley and A. W. Thomas, Angew. Chem., Int. Ed., 2003, 42, 5400-5449; (b) T. Itoh and T. Mase, Org. Lett., 2014, 6, 4587-4590; (c) M. A. Fernández-Rodríguez, Q. Shen and J. F. Hartwig, J. Am. Chem. Soc., 2006, 128, 2180-2181; (d) M. N. Birkholz, Z. Freixa and P. W. van Leeuwen, Chem. Soc. Rev., 2009, 38, 1099-1118; (e) I. P. Beletskaya and V. P. Ananikov, Chem. Rev., 2011, 111, 1596-1636.

2 (a) K. Pericherla, A. Jha and B. Khungar, Org. Lett., 2013, 15, 4304-4307; (b) Z. H. Yang, Y. An, L. Y. Chen, Z. Y. Shao and S. Y. Zhao, Adv. Synth. Catal., 2016, 358, 3869-3875; (c) K. Liao, F. Zhou, J. S. Yu, W. M. Gao and J. Zhou, Chem. Commun., 2015, 51, 16255-16258; (d) J. S. H. Yu, M. Huang, P. G. Ding, X. S. Hu, F. Zhou and J. Zhou, ACS Catal., 2016, 6, 5139-5144.

3 (a) R. S. Xu, J. P. Wan, H. Mao and Y. J. Pan, J. Am. Chem. Soc., 2010, 132, 15531-15533; (b) R. S. Xu, L. Yue and Y. J. Pan, Tetrahedron, 2012, 68, 5046-5052; (c) F. F. Duan, S. Q. Song and R. S. Xu, Chem. Commun., 2017, 53, 2737-2739; (d) R. R. Cai, Z. D. Zhou, Q. Q. Chai, Y. E. Zhu and R. S. Xu, RSC Adv., 2018, 8, 26828-26836.

4 (a) M. C. Carreño, Chem. Rev., 1995, 95, 1717-1760; (b) N. S. Simpkins, Sulphones in Organic Synthesis, Pergamon Press, Oxford, 1993; (c) M. N. Noshi, A. El-Awa, E. Torres and P. L. Fuchs, J. Am. Chem. Soc., 2007, 129, 11242-11247; (d) A. López-Pérez, R. Robles-Machín, J. Adrio and J. C. Carretero, Angew. Chem., Int. Ed., 2007, 46, 9261-9264.

5 (a) A. M. Myers, P. S. Charifson, C. E. Owens, et al., J. Med. Chem., 1994, 37, 4109-4117; (b) M. D. Collini and C. P. Miller, Tetrahedron Lett., 2001, 42, 8429-8843; (c) H. J. Song, M. Kai, X. D. Liu, W. Yin, Q. Zeng, X. J. Yao and R. Wang, Anti-Cancer Drugs, 2012, 1; (d) L. L. Liu, Q. Q. Deng, S. J. Weng, X. L. Yang and Y. M. Zhong, Neuroscience, 2016, 332, 53-60; (e) P. Zanos, R. Moaddel, 
P. J. Morris, L. M. Riggs, J. N. Highland, P. Georgiou, E. F. R. Pereira, E. X. Albuquerque, C. J. Thomas and C. A. Zarate, Pharmacol. Rev., 2018, 70, 621-660.

6 (a) C. P. Miller, M. D. Collini, H. A. Harris, and K. C. James, 5,11-dioxa-benzo[b]fluoren-10-one and 5-oxa-11-thia-benzo[b] fluoren-10-ones as estrogenic agents, US Pat., 20020183310,
2002; (b) M. D. Collini and C. P. Miller, Tetrahedron Lett., 2001, 42, 8429-8431; (c) J. D. Hepworth and B. M. Heron, Prog. Heterocycl. Chem., 1997, 9, 289-317; (d) M. A. Brimble, J. S. Gibson and J. Sperry, Comprehensive Heterocyclic Chemistry III, 2008, vol. 7, pp. 419-699. 